\title{
Active Power Filtering by a Flying-Capacitor Multilevel Inverter with Capacitor Voltage Balance
}

\author{
Junfei Hu, Li Zhang, S. J. Watkins \\ School of Electronics and Electrical Engineering, University of Leeds, UK \\ J.Hu03@leeds.ac.uk
}

\begin{abstract}
A new control strategy is developed for a four-level flying capacitor multilevel inverter to function as an active power filter (APF). This employs space vector modulation (SVM) according to capacitor voltage values at each level. It also applies a modified predictive current control law taking into account the derivative of the reference current. Simulation study has shown that the proposed scheme leads to high performance harmonic current compensation for both steady and transient state operations and capacitor voltages at all levels are well balanced.
\end{abstract}

\section{INTRODUCTION}

Active Power Filters (APF) is used to control reactive power flow and eliminate harmonic currents in power systems. They are going to be indispensable for maintaining a high quality power supply and will play an important role in the future due to the increasing integration of electric power generators powered by renewable energy sources within the power distribution infrastructure.

Conventional two-level inverter topology cannot be applied directly to high voltage power distribution systems which have voltage levels of tens of kilovolts because of limited device $V / I$ ratings and high $d V / d t$. A viable approach to high power conversion is by constructing multilevel inverters, in particular, the flying capacitor multilevel inverter (FCMI) proposed by Meynard, et al $[1,2,3]$. The FCMI has been used as a shunt power line conditioner and also as a unified power flow controller (UPFC) [3, 4]. The main challenge in using an FCMI as an APF lies in obtaining fast and accurate performance in harmonic compensation whilst maintaining the voltage across the floating or cell-capacitors at the appropriate constant levels. Large capacitor voltage swings may cause voltage stress across devices, consequently poor harmonic control performance and even inverter failure. Hitherto few published works have addressed this issue.

This paper investigates a new control scheme for a four-level FCMI functioning as a shunt active power filter. It employs a predictive current controller, and uses Space Vector Modulation (SVM) method to determine the inverter switching vectors and their corresponding duty cycles [5], the proposed control strategy has two novel features:

- employing capacitor voltage feedback signals to determine the inverter switching vectors and sequence, and

- Incorporating the rate of change of the reference current in the control algorithm to improve the accuracy in control at transient current changes.
The proposed FCMI-APF has been simulated to eliminate the load current harmonics in a small power system supplying a nonlinear load. The universal program system EMTP-ATP (Electromagnetic Transient Program-Alternative Transient Program.) has been used to conduct this study. The proposed control strategy has led to good performance harmonic elimination, particularly for transient operations.

The paper describes the principles of the APF control scheme. The specific SVM scheme for a four-level flyingcapacitor multilevel inverter is presented. Simulation result of the FCMI-APF controlling a power system will be presented and the features of the method in comparison to the other approaches will be highlighted.

\section{THE SYSTEM}

The power system simulated is shown in Figure 1. The threephase power source is separated from the load by the series impedance $L_{S}-R_{S}$. The nonlinear load is represented by a threephase thirsted controlled rectifier supplying an R-L load, and a three-phase load filter characterized as $\mathrm{L}_{\mathrm{L}}-\mathrm{R}_{\mathrm{L}}$ is used. The APF is a four-level (including 0 voltage level) flying-capacitor multilevel inverter as shown in Figure 1. It is shunt connected to the power line common coupling point $(\mathrm{CCP})$ on the load side through a filter featured as $L_{f}-R_{f}$. This is necessary for eliminating current ripples due to switching.

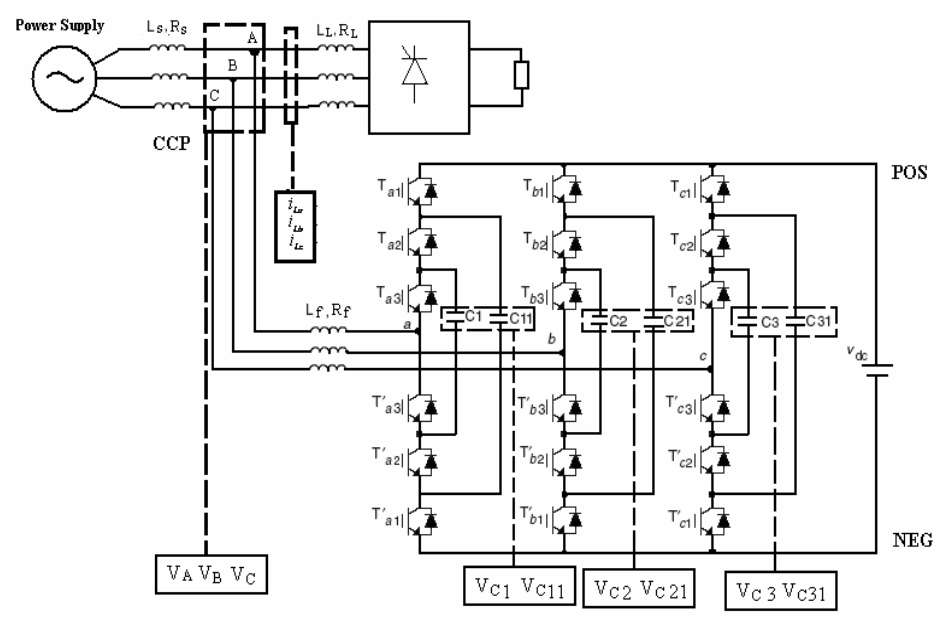

Figure 1. Schematic of the power system and a three-phase FCMI-based shunt APF. 


\section{THE PREDICTIVE CONTROL PRINCIPLE}

As is well known the APF control scheme consists of two processes. The first extracts the unwanted harmonic components from the measured load current. These are taken as the reference values for the second part which implements a feedback control scheme for canceling them from the power line current.

There are a number of methods for the first task, such as the instantaneous reactive power theory [7, 8]; however for simplicity the synchronous reference frame algorithm (SRF) $[9,10]$ is applied here. This assumes that the three phase voltages of the simulated power system are balanced and largely noise free hence they are represented as a space vector rotating around a stationary reference frame at the mains frequency. If the measured three-phase current vector is projected to a $\alpha-\beta$ plane, phase locked to the rotating voltage vector, according to Park's transformation it can be expressed as

$\left[\begin{array}{l}i_{p} \\ i_{q}\end{array}\right]=\left[\begin{array}{cc}\sin \omega t & -\cos \omega t \\ -\cos \omega t & -\sin \omega t\end{array}\right]\left[\begin{array}{l}i_{\alpha} \\ i_{\beta}\end{array}\right]$

where $i_{\alpha}, i_{\beta}$ are the two orthogonal current components of the three phase current vector $\vec{I}$ in SRF, ip and iq are defined as instantaneous active and reactive currents respectively and $\omega$ is the fundamental angular frequency of the AC system.

Both ip and iq are comprised of two components, the fundamental frequency component transformed to a DC quantity and the harmonic component as expressed below
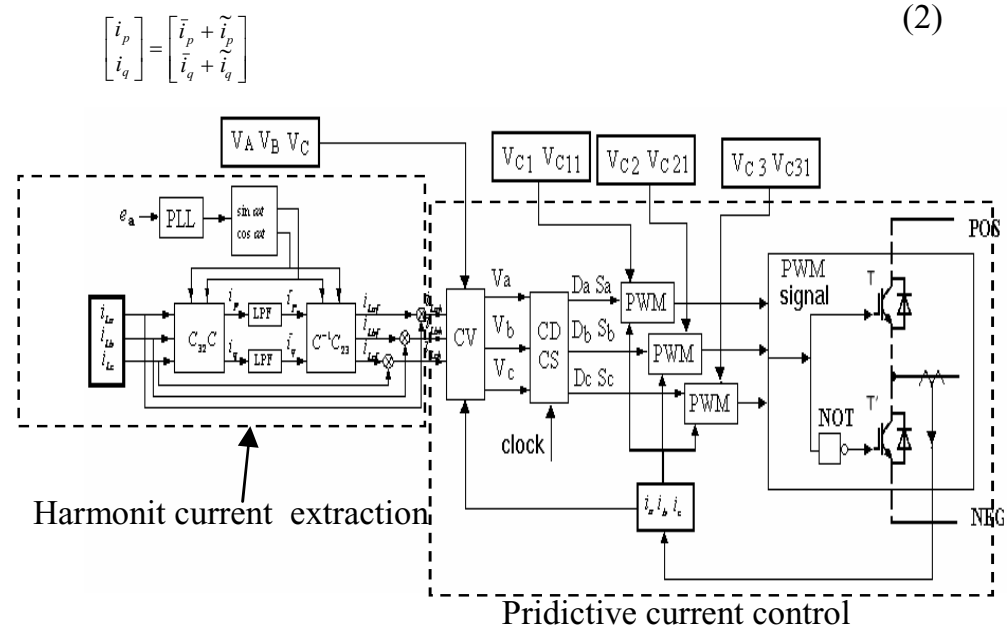

Figure 2. Control system diagram

Using a low-pass filter shown in Figure 2 we can extract the fundamental current. Its equivalent AC quantity $i_{L a f}, i_{L b f}, i_{L c f}$ can be derived by applying inverse Park's transform. Thus the load harmonic current components can be calculated as

$$
\left[\begin{array}{l}
i_{L a h} \\
i_{L b h} \\
i_{L c h}
\end{array}\right]=\left[\begin{array}{l}
i_{L a}-i_{L a f} \\
i_{L b}-i_{L b f} \\
i_{L c}-i_{L c f}
\end{array}\right]
$$

where $i_{L a}, i_{L b}$ and $i_{L c}$ are the three phase load current and $i_{L a h}$, $i_{L b h}$ and, $i_{L c h}$ are the harmonic components.

These extracted harmonic currents are applied as the reference currents for the APF control loop as shown in Figure 2. The aim of APF controller is to eliminate the harmonic current components from the load current. A predictive current control algorithm combining with the SVM scheme for FCMI is employed. The principle of predictive control scheme is well known. Having a model of the system to be controlled it estimates the appropriate control action to enable controlled variable to follow the desired value.

In this application the model of the system is the R-L impedance between the inverter output and power line common coupling point. The input and output variables are the inverter ac terminal voltage and current vectors, respectively. Thus the equation expressing the relationship between the input and output variables is given as

$$
\vec{e}-\vec{V}_{f}=L_{f} \cdot \frac{d \vec{i}_{L}}{d t}+R_{f} \cdot \vec{i}_{L}
$$

where $R_{f}$ and $L_{f}$ are the line/filter impedance between inverter ac terminal and CCP, $\vec{i}_{L}$ is the inverter current vector equivalent to the compensating current supplied by the APF, $\vec{e}$ and $\vec{V}_{f}$ are the voltage vectors at CCP and the inverter ac terminal respectively. $d \vec{i} / d t$ is the rate of change of current between two samples. During a short and finite switching period $T_{s}$, this can be approximated by ratio of difference terms as

$$
\frac{\Delta \vec{\Delta}_{L}}{T_{s}}=\frac{\vec{i}_{L}\left(t_{K}+T_{s}\right)-\vec{i}_{L}\left(t_{K}\right)}{T_{s}}
$$

Substituting $\vec{i}_{L}\left(t_{k}+T_{s}\right)$ with the estimated reference current and $\vec{i}_{L}\left(t_{k}\right)$ with the measured current value at $k^{\text {th }}$ time interval, the ac side voltage vector $\vec{V}_{f}$ at next sample can then be calculated as:

$$
\vec{V}_{f}\left(t_{K}+T_{S}\right)=\vec{e}\left(t_{k}\right)+\frac{L_{f}}{T_{s}} \vec{i}_{L}^{*}\left(t_{k}\right)+\left(R_{f}-\frac{L_{f}}{T_{s}}\right) \cdot \vec{i}_{L}\left(t_{k}\right)
$$

It is worth noting that the above algorithm does not work well under operating conditions where reference current changes rapidly. This is due to the natural delays in sampling steps caused by both the reference current and inverter reference voltage calculation processes.

This effect is revealed in this particular application when the firing angles of the three-phase rectifier become greater than $30^{\circ}$; the source current waveform contains undesirable sharp spikes as shown in Figure 5. To overcome this defect the new modified algorithm incorporates the rate of change of the reference current at the current and last samples into Equ(6), subsequently we have

$\vec{V}_{f}=\vec{e}\left(t_{k}\right)+\frac{L_{f}}{T_{s}} \vec{i}_{L}^{*}\left(t_{k}\right)+\left(R_{f}-\frac{L_{f}}{T_{s}}\right) \cdot \vec{i}_{L}\left(t_{k}\right)+n \cdot\left[\vec{i}_{L}^{*}\left(t_{k}\right)-\vec{i}_{L}\left(t_{k}\right)\right]+m \cdot\left[\vec{i}_{L}^{*}\left(t_{k}\right)-\vec{i}_{L}^{*}\left(t_{k-1}\right)\right]$

where $n$ and $m$ are the weighting factors for newly added terms. Similar to adding derivative terms in a $\mathrm{P}+\mathrm{I}$ controller, these terms enable the controller responding promptly to reference current variations. However they also make the controller sensitive to measurement noise, which may lead the 
system unstable. Thus it is important to tune $\mathrm{m}$ and $\mathrm{n}$ factors carefully to achieve the desired transient performance.

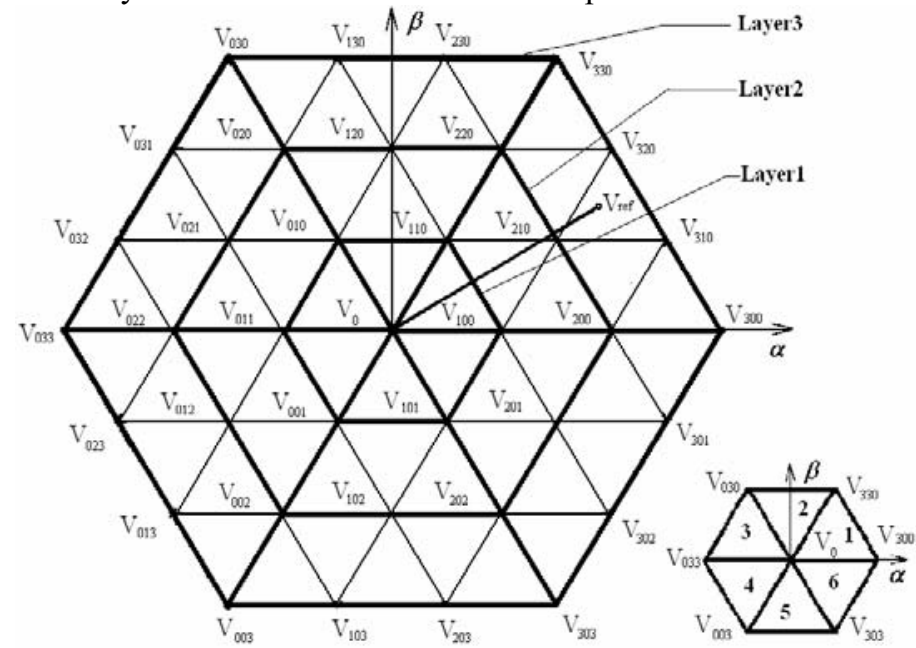

Figure 3. Switching vectors in a multilayer hexagon

\section{Space Vectors Modulation SCHEME}

Once obtaining inverter voltage vector the SVM scheme is applied to determine the switching vectors and calculate their corresponding durations. The method of vector selection is described below taking a four-level three-phase FCMI as the example.

In this case there are, in total, 40 switching vectors, 36 active and 4 zero ones. The spread of these vectors within a bounded three-layer hexagon is shown in Figure 3. Selection of the switching vectors at every sample interval is based on the location of $V_{\text {ref }}$ in the hexagon, which is coded according to the 54 small triangles (see Figure 3), but also importantly on the measured capacitor voltage levels. Each of these triangles has three adjacent active switching vectors. Those of them connecting the middle and low voltage levels involve either a capacitor being charged by the power source or the other being discharged through the load. A look-up table is set up to store the charging and discharging features of all the switching vectors.

The vectors are arranged according to their layers from 1 to 3. A vector table is established with the phase leg output voltage levels as shown in Table I. For example, the voltage of the four-level inverter phase leg $a$ output with respect to the negative DC rail, $V_{a N}$, can be synthesized to the following voltage level:

1) For voltage level $0, V_{a N}=0$

2) For voltage level $1, V_{a N}=V_{d c} / 3$.

3) For voltage level 2, $V_{a N}=2 V_{d c} / 3$.

4) For voltage level $3, V_{a N}=V_{d c}$.

The triangle is formed by state vectors $V_{a}, V_{b}$, and $V_{z}$. The active time for the state vectors can be given by the following formulae,

$$
T_{a} \cdot \vec{V}_{a}+T_{b} \cdot \vec{V}_{b}+T_{z} \cdot \vec{V}_{z} \approx T_{s} \cdot \vec{V}
$$

$$
T_{S}=T_{a}+T_{b}+T_{z}
$$

where $T_{s}$ is the carrier period, $T_{a}$, is the time interval for $V_{a_{\rightarrow}} T_{b}$ and $T_{z}$ are the time intervals for $V_{b}$, and $V_{z}$, respectively, $\vec{V}$ is the target output space vector. The duty time equations for sectors 1 to 6 are listed in Table II, where $k$ is equal to 3 and $M$ is the modulation index, defined as the ratio between the magnitudes of the modulating waveform and the carrier signal.

TABLE I

\begin{tabular}{|c|c|c|c|c|c|}
\hline \multicolumn{2}{|c|}{ Level 1} & \multicolumn{4}{|c|}{ Level 2} \\
\hline $\mathrm{V}$ & $\mathrm{S}$ & $\mathrm{V}$ & $\mathrm{S}$ & $\mathrm{V}$ & $\mathrm{S}$ \\
\hline$V_{0}$ & $\begin{array}{lll}0 ; & 0 ; & 0 \\
1 ; & 1 ; & 1 \\
2 ; & 2 ; & 2 \\
3 ; & 3 ; & 3\end{array}$ & $V_{200}$ & $\begin{array}{lll}2 ; & 0 ; \\
3 ; 1 ; 1 & 1\end{array}$ & $V_{022}$ & 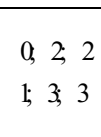 \\
\hline$V_{100}$ & $\begin{array}{lll}1 ; & 0 ; & 0 \\
2 ; & 1 ; & 1 \\
3 ; & 2 ; & 2\end{array}$ & $V_{210}$ & $\begin{array}{lll}2 ; & 1 ; & 0 \\
3 & 2 ; & 1\end{array}$ & $V_{012}$ & $\begin{array}{lll}0 ; & 1 ; & 2 \\
1 ; & 2 ; & 3\end{array}$ \\
\hline$V_{110}$ & $\begin{array}{lll}1 ; & 1 ; & 0 \\
2 ; & 2 ; & 1 \\
3 ; & 3 ; & 2\end{array}$ & $V_{220}$ & $\begin{array}{lll}2 & 2 & 0 \\
3 & 3 & 1\end{array}$ & $V_{002}$ & $\begin{array}{lll}0 ; & 0 ; & 2 \\
1 ; & 1 ; & 3\end{array}$ \\
\hline$V_{010}$ & $\begin{array}{lll}0 ; & 1 ; & 0 \\
1 ; & 2 ; & 1 \\
2 ; & 3 ; & 2\end{array}$ & $V_{120}$ & $\begin{array}{lll}1 ; & 2 ; 0 \\
2 ; & 3 & 1\end{array}$ & $V_{102}$ & $\begin{array}{lll}1 ; & 0 ; & 2 \\
2 ; & 1 ; & 3\end{array}$ \\
\hline$V_{0 I I}$ & $\begin{array}{lll}0 ; & 1 ; 1 \\
1 ; & 2 ; & 2 \\
2 ; & 3 ; & 3\end{array}$ & $V_{020}$ & $\begin{array}{lll}0 ; & 2 ; & 0 \\
1 ; & 3 ; & 1\end{array}$ & $V_{202}$ & $\begin{array}{lll}2 ; & 0,2 \\
3 ; 1 ; & 3\end{array}$ \\
\hline$V_{001}$ & $\begin{array}{lll}0 ; & 0 ; & 1 \\
1 ; & 1 ; & 2 \\
2 ; & 2 ; & 3\end{array}$ & $V_{021}$ & $\begin{array}{lll}0 & 2 & 1 \\
1 & 3 & 2\end{array}$ & $V_{201}$ & $\begin{array}{lll}2 & 0 & 1 \\
3 & 1 & 2\end{array}$ \\
\hline$V_{101}$ & $\begin{array}{lll}1 ; & 0 ; & 1 \\
2 ; & 1 ; & 2 \\
3 ; & 2 ; & 3\end{array}$ & & & & \\
\hline & & & & & \\
\hline $\mathrm{V}$ & $\mathrm{S}$ & $\mathrm{V}$ & $\mathrm{S}$ & $\mathrm{V}$ & $\mathrm{S}$ \\
\hline$V_{300}$ & $3 ; 0 ; 0$ & $V_{030}$ & $0 ; 3 ; 0$ & $V_{003}$ & $0 ; 0 ; 3$ \\
\hline$V_{310}$ & $3 ; 1 ; 0$ & $V_{031}$ & $0 ; 3 ; 1$ & $V_{103}$ & $1 ; 0 ; 3$ \\
\hline$V_{320}$ & $3 ; 2 ; 0$ & $V_{032}$ & $0 ; 3 ; 2$ & $V_{203}$ & $2 ; 0 ; 3$ \\
\hline$V_{330}$ & $3 ; 3 ; 0$ & $V_{033}$ & $0 ; 3 ; 3$ & $V_{303}$ & $3 ; 0 ; 3$ \\
\hline$V_{230}$ & $2 ; 3 ; 0$ & $V_{023}$ & $0 ; 2 ; 3$ & $V_{302}$ & $3 ; 0 ; 2$ \\
\hline$V_{130}$ & $1 ; 3 ; 0$ & $V_{013}$ & $0 ; 1 ; 3$ & $V_{301}$ & $3 ; 0 ; 1$ \\
\hline
\end{tabular}

SPACE VECTORS FOR A FOUR-LEVEL INVERTER

Using the capacitor voltage feedback signal we examine the extent of relevant capacitor voltage deviations from their respective desired levels. Subsequently we determine the switching vectors and their sequence of implementation in the inverter appropriate for minimizing capacitor voltage swings. The above operation is included in block $C V$ in Figure 2. Calculation of the duty cycles for the selected vectors is then followed as indicated in block $C D / C S$ in the figure 2 . 


\section{Simulation Results}

TABLE II

FORMULAE FOR DUTY CYCLE CALCULATION

\begin{tabular}{|c|c|c|c|}
\hline $\begin{array}{c}\text { Sector, } \\
\mathrm{n}\end{array}$ & $\begin{array}{c}\text { Phase } \\
\text { Angle, } \theta\end{array}$ & Vector & Sector Duty Equation \\
\hline \multirow[t]{2}{*}{1} & \multirow[t]{2}{*}{$\begin{array}{c}0 \leq \theta< \\
\pi / 3\end{array}$} & $\begin{array}{l}V_{k a 0}, \\
V_{k b 0} \\
V_{z a 0}\end{array}$ & $\begin{array}{l}T_{a}=\frac{\sqrt{3}}{2} k \cdot M \cdot T_{s} \cdot \cos \left(\theta+\frac{\pi}{6}\right)+(a-k+1) T_{s} \\
T_{b}=\frac{\sqrt{3}}{2} k \cdot M \cdot T_{s} \cdot \sin \theta-a \cdot T_{s}\end{array}$ \\
\hline & & $\begin{array}{l}V_{z b 0}, \\
V_{k b 0} \\
V_{z a 0}\end{array}$ & $\begin{array}{l}T_{a}=\frac{\sqrt{3}}{2} k \cdot M \cdot T_{s} \cdot \sin \left(\theta-\frac{\pi}{3}\right)+(k-a-1) T_{s} \\
T_{b}=\frac{\sqrt{3}}{2} k \cdot M \cdot T_{s} \cdot \cos \left(\theta-\frac{\pi}{6}\right)-(k-1) \cdot T_{s}\end{array}$ \\
\hline \multirow[t]{2}{*}{2} & \multirow[t]{2}{*}{$\begin{array}{l}\pi / 3 \leq \theta \\
<2 \pi / 3\end{array}$} & $\begin{array}{l}V_{a k 0,} \\
V_{b k 0,} \\
V_{a z 0}\end{array}$ & $\begin{array}{l}T_{a}=\frac{\sqrt{3}}{2} k \cdot M \cdot T_{s} \cdot \sin \left(\theta-\frac{2 \pi}{3}\right)-(k-a) \cdot T_{s} \\
T_{b}=\frac{\sqrt{3}}{2} k \cdot M \cdot T_{s} \cdot \cos \left(\theta-\frac{\pi}{6}\right)+(1-a) T_{s}\end{array}$ \\
\hline & & $\begin{array}{l}V_{a k l}, \\
V_{a k 0,} \\
V_{a z 0}\end{array}$ & $\begin{array}{l}T_{a}=\frac{\sqrt{3}}{2} k \cdot M \cdot T_{s} \cdot \cos \left(\theta-\frac{\pi}{2}\right)-(k-1) \cdot T_{s} \\
T_{b}=\frac{\sqrt{3}}{2} k \cdot M \cdot T_{s} \cdot \sin \left(\theta-\frac{2 \pi}{3}\right)+a \cdot T_{s}\end{array}$ \\
\hline \multirow[t]{2}{*}{3} & \multirow[t]{2}{*}{$\begin{array}{c}2 \pi / 3 \leq \theta \\
<\pi\end{array}$} & $\begin{array}{l}V_{0 k a,} \\
V_{0 k b}, \\
V_{0 z a}\end{array}$ & $\begin{array}{l}T_{a}=\frac{\sqrt{3}}{2} k \cdot M \cdot T_{s} \cdot \cos \left(\theta-\frac{\pi}{2}\right)+(a-k+1) T_{s} \\
T_{b}=\frac{\sqrt{3}}{2} k \cdot M \cdot T_{s} \cdot \sin \left(\theta-\frac{2 \pi}{3}\right)-a \cdot T_{s}\end{array}$ \\
\hline & & $\begin{array}{l}V_{0 z b,} \\
V_{0 k b}, \\
V_{0 z a} \\
\end{array}$ & $\begin{array}{l}T_{a}=\frac{\sqrt{3}}{2} k \cdot M \cdot T_{s} \cdot \sin (\theta-\pi)+(k-a-1) T_{s} \\
T_{b}=\frac{\sqrt{3}}{2} k \cdot M \cdot T_{s} \cdot \cos \left(\theta-\frac{5 \pi}{6}\right)-(k-1) \cdot T_{s}\end{array}$ \\
\hline \multirow[t]{2}{*}{4} & \multirow[t]{2}{*}{$\begin{array}{c}\pi \leq \theta< \\
4 \pi / 3\end{array}$} & $\begin{array}{l}V_{0 a k}, \\
V_{0 b k} \\
V_{0 a z}\end{array}$ & $\begin{array}{l}T_{a}=\frac{\sqrt{3}}{2} k \cdot M \cdot T_{s} \cdot \sin (\theta-\pi)-(k-a) \cdot T_{s} \\
T_{b}=\frac{\sqrt{3}}{2} k \cdot M \cdot T_{s} \cdot \cos \left(\theta-\frac{5 \pi}{6}\right)+(1-a) T_{s}\end{array}$ \\
\hline & & $\begin{array}{l}V_{\text {lak }} \\
V_{\text {oak }} \\
V_{\text {oaz }} \\
\end{array}$ & $\begin{array}{l}T_{a}=\frac{\sqrt{3}}{2} k \cdot M \cdot T_{s} \cdot \cos \left(\theta-\frac{7 \pi}{6}\right)-(k-1) \cdot T_{s} \\
T_{b}=\frac{\sqrt{3}}{2} k \cdot M \cdot T_{s} \cdot \sin \left(\theta-\frac{4 \pi}{3}\right)+a \cdot T_{s}\end{array}$ \\
\hline \multirow[t]{2}{*}{5} & \multirow[t]{2}{*}{$\begin{array}{c}4 \pi / 3 \leq \theta \\
<5 \pi / 3\end{array}$} & $\begin{array}{l}V_{a 0 k}, \\
V_{b 0 k}, \\
V_{a 0 z}\end{array}$ & $\begin{array}{l}T_{a}=\frac{\sqrt{3}}{2} k \cdot M \cdot T_{s} \cdot \cos \left(\theta-\frac{7 \pi}{6}\right)+(a-k+1) T_{s} \\
T_{b}=\frac{\sqrt{3}}{2} k \cdot M \cdot T_{s} \cdot \sin \left(\theta-\frac{4 \pi}{3}\right)-a \cdot T_{s}\end{array}$ \\
\hline & & $\begin{array}{l}V_{b 0 z,} \\
V_{b 0 k,} \\
V_{a 0 z}\end{array}$ & $\begin{array}{l}T_{a}=\frac{\sqrt{3}}{2} k \cdot M \cdot T_{s} \cdot \sin \left(\theta-\frac{5 \pi}{3}\right)+(k-a-1) T_{s} \\
T_{b}=\frac{\sqrt{3}}{2} k \cdot M \cdot T_{s} \cdot \cos \left(\theta-\frac{3 \pi}{2}\right)-(k-1) \cdot T_{s}\end{array}$ \\
\hline \multirow[t]{2}{*}{6} & \multirow[t]{2}{*}{$\begin{array}{l}5 \pi / 3 \leq \theta \\
<2 \pi\end{array}$} & $\begin{array}{l}V_{k 0 a}, \\
V_{k 0 b}, \\
V_{z 0 a}\end{array}$ & $\begin{array}{l}T_{a}=\frac{\sqrt{3}}{2} k \cdot M \cdot T_{s} \cdot \sin \left(\theta-\frac{5 \pi}{3}\right)-(k-a) \cdot T_{s} \\
T_{b}=\frac{\sqrt{3}}{2} k \cdot M \cdot T_{s} \cdot \cos \left(\theta-\frac{3 \pi}{2}\right)+(1-a) T_{s}\end{array}$ \\
\hline & & $\begin{array}{l}V_{k l a}, \\
V_{k 0 a}, \\
V_{z 0 a}\end{array}$ & $\begin{array}{l}T_{a}=\frac{\sqrt{3}}{2} k \cdot M \cdot T_{s} \cdot \cos \left(\theta-\frac{7 \pi}{6}\right)-(k-1) \cdot T_{s} \\
T_{b}=\frac{\sqrt{3}}{2} k \cdot M \cdot T_{s} \cdot \sin \left(\theta-\frac{4 \pi}{3}\right)+a \cdot T_{s}\end{array}$ \\
\hline
\end{tabular}

\section{CAPACITOR VOLTAGE BALANCING CONTROL}

Since there are two floating capacitors in each inverter limb, the voltage balance of these capacitors (six of them) is a key issue for the system to operate as desired. In this work, a voltage feedback scheme is applied. This measures the capacitor voltages at every sample interval and compared with their desired values. The errors are applied to determine the appropriate vector and switching combination at the corresponding sample interval. Especially for voltage level 1 and 2, there are different switching combination to charge and discharge the capacitor. For example if the voltage of $\mathrm{C}_{1}$ is lower than $1 / 3 \mathrm{~V}_{\mathrm{DC}}$ by a predefined error band a switch combination will be chosen such that it leads to $C_{1}$ being charged, while the inverter output voltage follows the desired value. On the other hand if voltage of $\mathrm{C}_{1}$ is higher than desired, the switch combination selected will cause it to discharge through the load.
The above described control method has been applied to the simulated power system shown in Figure 1. The voltage rating is set to $600 \mathrm{~V}$ (peak-peak), $50 \mathrm{~Hz}$ and current rating $150 \mathrm{~A}$. The power line impedance values are defined as $R s=0.1 \Omega$ and $L s=$ $0.0085 \mathrm{mH}$. The load resistance $R$ is $2 \Omega$. The load input filter parameters are $R_{r}=0.1 \Omega$ and $L_{r}=0.3 \mathrm{mH}$. The resistance and inductance of the APF filter are $0.1 \Omega$ and $0.8 \mathrm{mH}$, respectively. The results of simulation are shown in Figures 4-6. In Figure 5, the modified algorithm is compared with the method when derivative terms are not used. It is shown clearly that the latter leads to spikes on the peak points of current waveform. In contrast, when using the proposed method, these spikes are significantly attenuated giving a superior current waveform. The waveforms in Figures 6(a)-(f) are for transient current responses with $\alpha$ changing from $0^{\circ}$ to $30^{\circ}$ and from $30^{\circ}$ to $60^{\circ}$. Figures 6(a) and (d) show load current, (b) and (e) give APF compensating currents respectively for both $\alpha$ values, and (c) and (f) are the power line current waveforms. Clearly fast harmonic compensation has been achieved in both cases using the proposed control scheme. The performance of the proposed APF is satisfactory while the flying-capacitor voltages at both levels 1 and 2 are well balanced as shown in Figure 4.

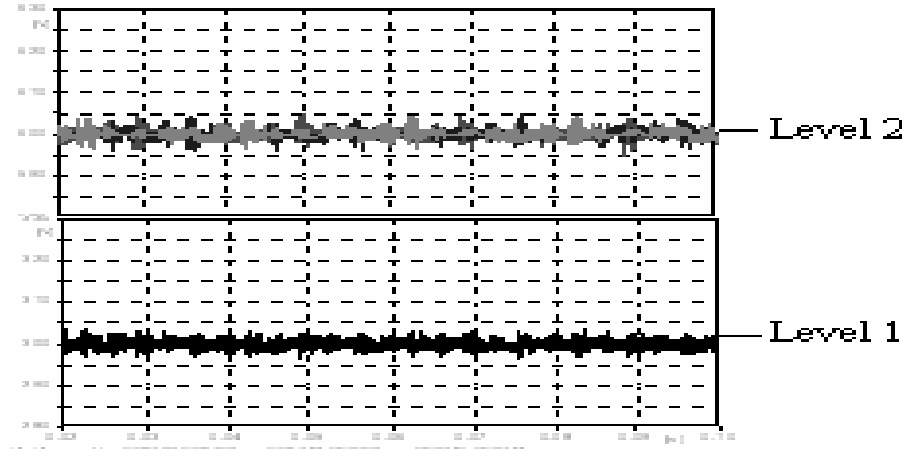

Figure 4 Balanced flying capacitor voltages

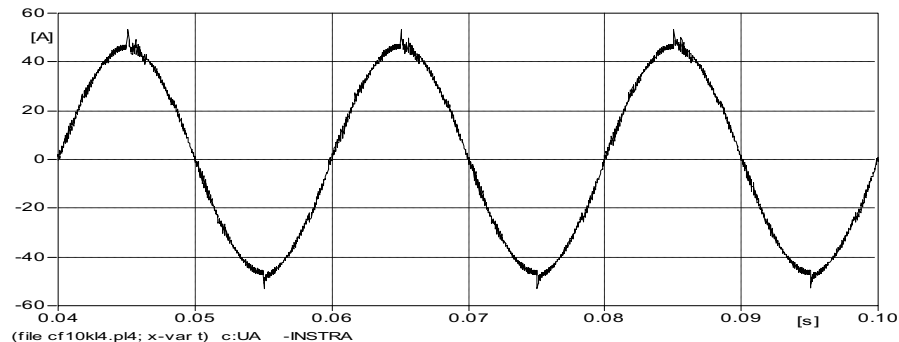

(a)Power line current with modified algorithm

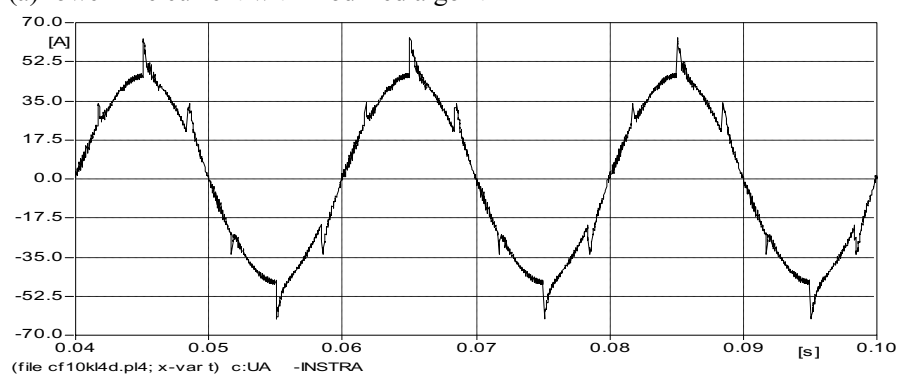

(b)Power line current with conventional algorithm

Figure 5: Simulation results 


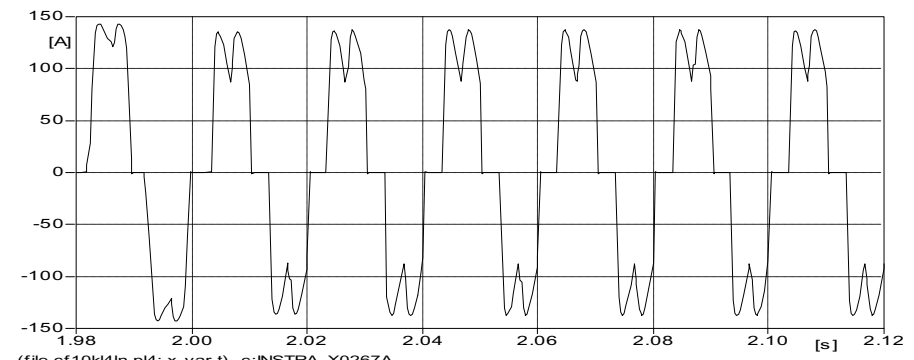

(a)

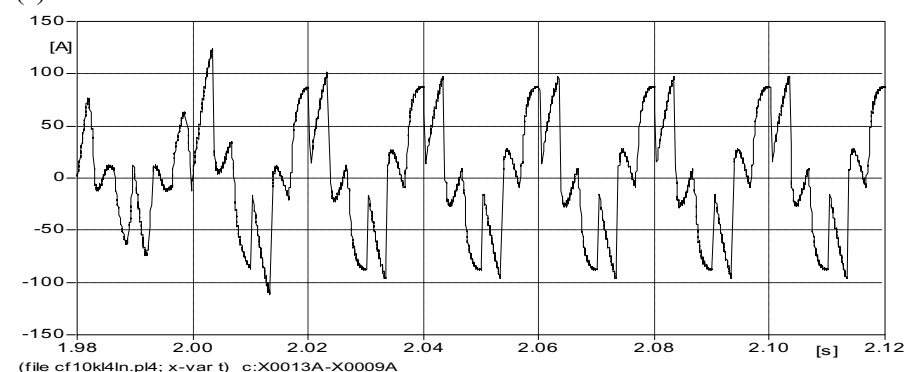

(b)

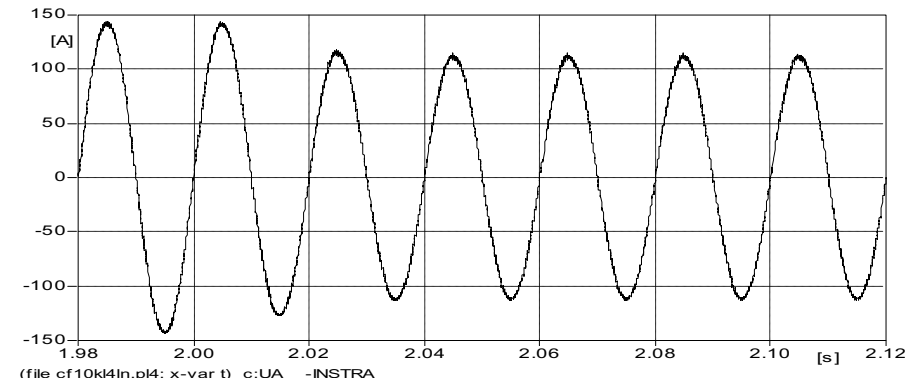

(file cf10k410 p14: $x$-var t) $c:$ HA - INSTRA

(c)

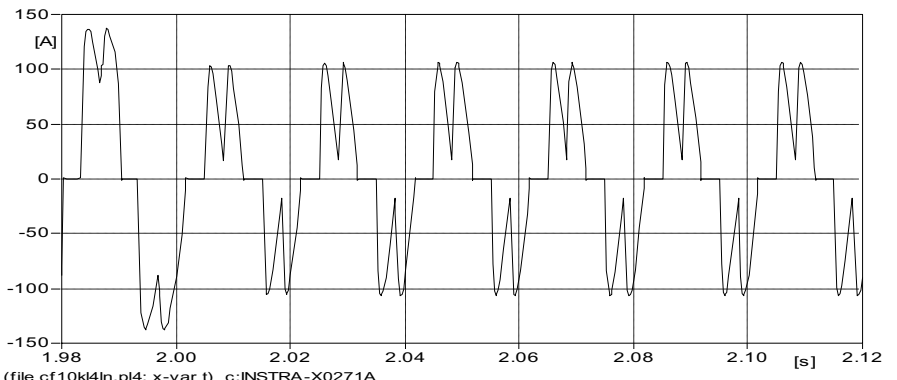

(d)

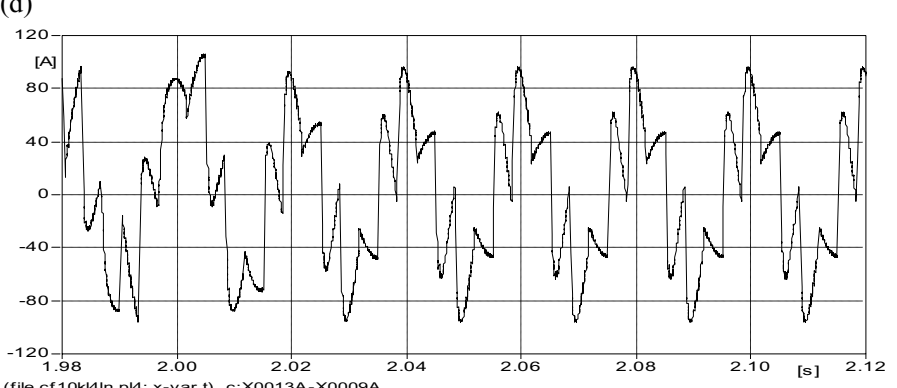

(e)

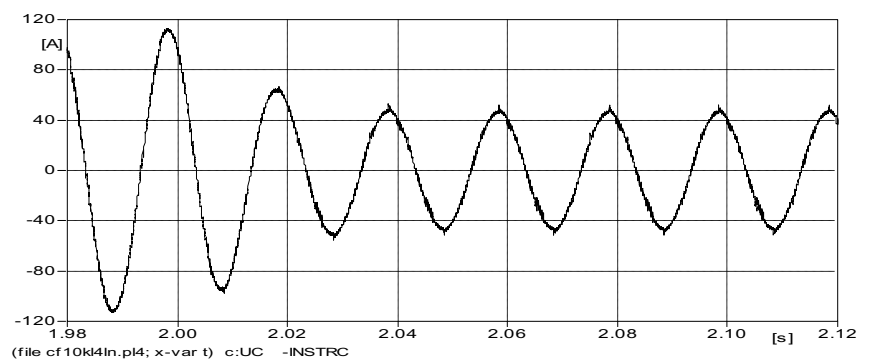

(f)

Figure 6 Transient response for $\alpha$ from $0^{\circ}$ to $30^{\circ}$; ((a) Load current; (b) APF current; (c)Compensated source current :

Transient response for $\alpha$ from $30^{\circ}$ to $60^{\circ}$ (d)Load current; (e) APF current; (f)Compensated source current

\section{CONCLUSION}

The paper presented an FCMI-APF for harmonic compensation. The predictive control scheme has incorporated derivative terms and SVM method for inverter switching control. Capacitor voltage values are feedback to the control loop to assist switching vector selection at each sample. Simulation result has shown that the proposed method is capable to give desired performance for both steady and transient operations.

\section{REFERENCES}

[1] Meynard, T.A. and Foch, H., "Dipositif électronique de conversion d'énergie électrique", French Patent No. 2679715B1, Filed 25th July 1991, Issued 29th January 1993. (WO93/02501A1, "Electronic device for converting electrical energy").

[2] Meynard, T.A. and Foch, H., Multi-level choppers for high voltage applications, EPE Journal, Vol. 2, No. 1, pp. $45-50$.

[3] Liang, Y.; Nwankpa, C.O., A power-line conditioner based on flyingcapacitor multilevel voltage-source converter with phase-shift SPWM, Industry Applications, IEEE Transactions on Vol. 36, No. 4, pp. 965-971

[4] L. Xu and V.G. Agelidis, Flying capacitor multilevel PWM converter based UPFC, IEE Proc. Electr. Power Appl., Vol 149, No. 4, pp. 304-310

[5] L. Xiao, L.Zhang, "A Space Vector-Based Deadbeat Controller for Shunt Active power Filters"; EPE'97, pp 4.864-4.869

[6] Watkins, S.J.; Zhang, L.; Multilevel space vector PWM control schemes for a flying-capacitor inverter; PEMD 2004, Vol. 1, pp:12 - 17

[7] H. Akagi, Y. Kanazawa, and A. Nabae, "Generalized theory of the instantaneous reactive power in three-phase circuits," in Proc. I983 Int. Power Electronics Conf, Tokyo, Japan, 1983, pp. 1375-1386.

[8] Akagi, H.; "Active Harmonic Filters"; Proceedings of the IEEE Volume 93, Issue 12, Dec. 2005 Page(s):2128 - 2141

[9] S. Bhattacharya, M. Divan, and B. Benerjee, Synchronous Reference Frame Harmonic Isolator Using Series Active Filter, EPE'91, Vol. 3, pp. $30-35$

[10] Bhattacharya, S., Divan, D., Synchronous frame based controller implementation for a hybrid series active filter system, IEEE/IAS Annual Meeting 1995, pp2531-2540 